$\begin{array}{lllllllllllllllllllllllll}\text { A C T A } & \text { C H E M I C A } & \text { S C A N D I N A V I C A } & 13 & (1959) & 365-376\end{array}$

\title{
On the Defect Structure of Rutile
}

\author{
TOR HURLEN
}

Central Institute for Industrial Research, Blindern, Oslo, Norway

\begin{abstract}
From the point of view of its importance to the understanding of the oxidation behaviour of titanium and titanium alloys, a theoretical reinvestigation is made of the defect structure of rutile with special emphasis on what is to be expected from the ideal rutile structure itself.

A discussion is moreover given of previous experimental results on the subject, and it is concluded that most of the available data are possibly best explained by assuming the defect structure to be a combination of a non-stoichiometric and a stoichiometric one, both in. volving titanium interstitial ions.
\end{abstract}

\subsection{INTRODUCTION}

Tt is well known that the oxidation of a metal usually leads to the formation I of a more or less compact oxide film on the metal surface, and that the further oxidation requires passage through this film either of metal outwards or of oxygen inwards. Very often, the rate of transport of material through the oxide lattice itself (volume diffusion) is found to be determining for the oxidation resistance of the metal (Wagner ${ }^{1}$ mechanism of oxidation).

It is further known that the volume diffusion in ionic crystals depends on the defect structure of the crystals, and that the defect structure in many cases may be partly controlled by the incorporation of foreign ions in the lattice (Wagner-Hauffe ${ }^{2}$ approach to alloy oxidation).

The application of this basic knowledge to the oxidation resistance of a special metal and to its improvement by alloying, is greatly facilitated by the understanding of the defect structure of the pure oxide(s) in question.

Rutile has been shown ${ }^{3,4}$ to be the main oxide formed on titanium under the most actual oxidation conditions. This oxide is of an $n$-conducting ${ }^{5}$, oxygen deficient ${ }^{5-7}$ type. It does not seem well recognized, however, whether the latter is due to the presence of oxygen vacancies or of titanium interstitials in the rutile lattice.

The purpose of the present work is to elucidate this matter and to gain the best possible understanding of the defect structure of rutile from already known experimental data. Our hope is that this might facilitate the interpretation and understanding of the oxidation behaviour of titanium and titanium alloys.

Acta Chem. Scand. 13 (1959) No. 2 


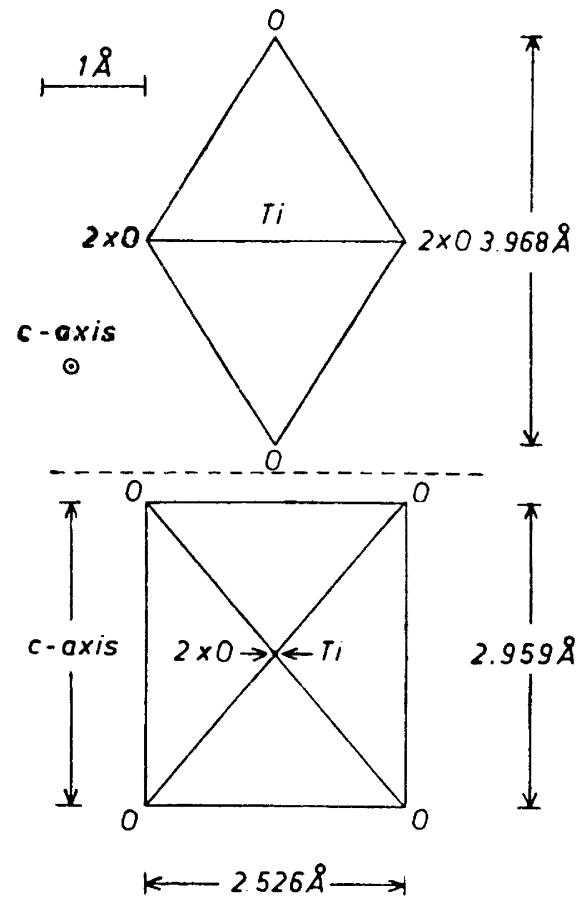

Fig. 1. The shape and size of the $\mathrm{TiO}_{8}$ octahedra in rutile.

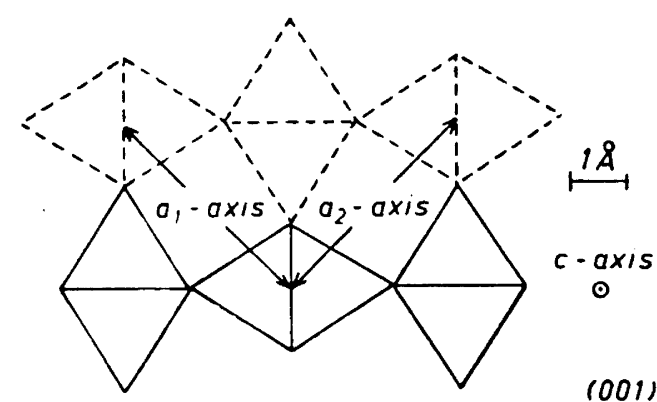

(001)

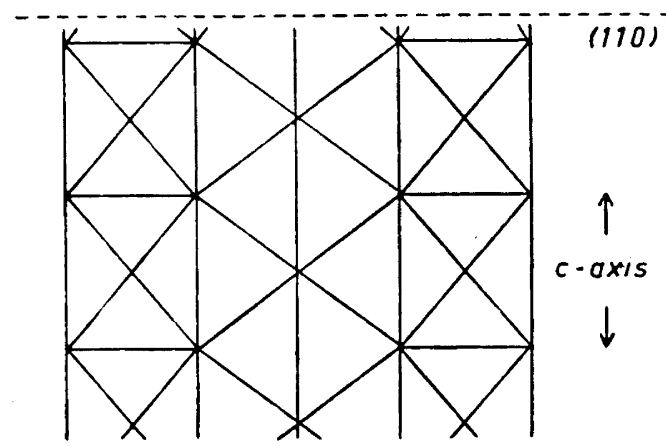

Fig. 2. The octahedron model of rutile.

\subsection{THE RUTILE STRUCTURE}

Titanium forms a number of different oxides, and so far the following ones have been identified ?: $\mathrm{Ti}_{2} \mathrm{O}, \mathrm{Ti}_{3} \mathrm{O}_{2}, \mathrm{TiO}, \mathrm{Ti}_{2} \mathrm{O}_{3}, \mathrm{Ti}_{3} \mathrm{O}_{5}, \mathrm{Ti}_{n} \mathrm{O}_{2 n-1}(n=4,5,6$, 7, 8, 9 and 10), and $\mathrm{TiO}_{2}$. The lowest of these oxides, $\mathrm{Ti}_{2} \mathrm{O}$, has a structure which may be represented by $\mathrm{OTi}_{6}$-octahedra sharing corners and edges. The other titanium oxides may be considered to consist of $\mathrm{TiO}_{6}$-octahedra sharing corners, edges, and possibly faces in various ways.

From X-ray data on $\mathrm{TiO}_{2}$ (rutile) is found that its $\mathrm{TiO}_{6}$-octahedra are not exactly regular. Fig. 1 shows a rutile octahedron in two projections, and the dimensions given are those determined by Magnéli and co-workers ${ }^{7}$, which are in close agreement with those determined by Cromer and Herrington ${ }^{8}$. The octahedra are characterized by:

$4 \mathrm{Ti}-\mathrm{O}$ distances of $1.946 \AA$

$2 \mathrm{Ti}-\mathrm{O}$ distances of $1.984 \AA$

$8 \mathrm{O}-\mathrm{O}$ distances of $2.779 \AA$

$2 \mathrm{O}-\mathrm{O}$ distances of $2.959 \AA$

$2 \mathrm{O}-\mathrm{O}$ distances of $2.526 \AA$

Acta Chem. Scand. 13 (1959) No. 2 
In rutile, these octahedra are joined by edges and corners in such a way as to make each oxygen ion belong to three neighbouring octahedra. This type of octahedron coupling is shown in Fig. 2, where also the direction and length of the crystallographic axes in relation to the octahedra are indicated.

From Fig. 2 is easily seen that this type of coupling between the octahedra results in a kind of parallel octahedron chains in which neighbouring octahedra have an edge in common. These chains are further joined to each other so that the side corners in one chain's octahedra become top corners in a neighbouring chain's octahedra and vice versa. In rutile, the $c$-axis becomes parallel to the octahedron chains.

From Fig. 2 is further seen that this type of coupling between the chains results in the existence of just as many "open" channels parallel to the $c$-axis as there are octahedron chains, and in Fig. 3 is shown that such a channel contains a row of octahedral interstitial positions for titanium. The distance between these positions (in direction of the $c$-axis) is half only of that between normal titanium lattice positions in an octahedron chain. The "interstitial" oxygen octahedra are all of the same shape and size, and along the channels every second one is turned $90^{\circ}$ around the $c$-axis in relation to the rest of them, and they are placed half way into each other. From Fig. 3 is further seen that an "interstitial" $\mathrm{O}_{6}$-octahedron shares two faces and four edges with neighbouring $\mathrm{TiO}_{6}$-octahedra.

The shape and size of the "interstitial" $\mathrm{O}_{6}$-octahedra are shown in Fig. 4. By comparing with Fig. 1 , it is seen that these $\mathrm{O}_{6}$-octahedra differ distinctly from the normal $\mathrm{TiO}_{6}$-octahedra in rutile, especially in being larger. The volume of a $\mathrm{TiO}_{6}$-octahedron is about $9.89 \AA^{3}$, whereas the volume of an "interstitial" $\mathrm{O}_{6}$-octahedron is about $10.91 \AA^{3}$.

The rutile structure also contains tetrahedral interstitial positions, and it is easily seen that there are just as many of these as there are octahedral interstitial positions (twice that of normal titanium lattice positions). The tetrahedral positions are not arranged along channels of any kind, and as titanium is not known to occur with the coordination number four, these positions seem to be of minor interest.

\subsection{THE DEFECT STRUCTURE OF RUTILE}

The defects or imperfections which can exist in crystal lattices can be classified as reversible (ions in interstitial positions and ion vacancies connected with an equivalent number of quasi-free electrons and electron holes) or irreversible (flaws, cracks, dislocations). The present discussion is confined to the former class of defects.

Ehrlich ${ }^{6}$ reported that rutile exists over a rather wide oxygen concentration range $\left(\mathrm{TiO}_{1.90}-\mathrm{TiO}_{2.00}\right)$, whereas Magnéli and coworkers ${ }^{7}$ found that the minimum content of oxygen is higher than that corresponding to $\mathrm{TiO}_{1.96}$. These investigators seem to agree, however, that the higher oxygen limit corresponds to the stoichiometric composition $\mathrm{TiO}_{2.00}$. 
The possible non-stoichiometric defect equilibria in rutile may be represented by the following equations:

$$
\begin{aligned}
& \mathrm{Nil} \rightleftharpoons \mathrm{O}_{\mathrm{v}} \pm \dot{\mathrm{v}} \pm \vec{e}+\frac{1}{2} \mathrm{O}_{2}(\mathrm{~g}) \\
& \mathrm{Nil} \rightleftharpoons \mathrm{O}_{\mathrm{v}} \cdot e^{-}+\frac{1}{2} \mathrm{O}_{2}(\mathrm{~g}) \\
& \mathrm{Nil} \rightleftharpoons \mathrm{O}_{\mathrm{v}} \cdot 2 e^{-}+\frac{1}{2} \mathrm{O}_{2}(\mathrm{~g})
\end{aligned}
$$

for anion vacancies $\left(\mathrm{O}_{\mathrm{v}}\right)$ with or without trapped electrons ( $A V$-type defects), and by

$$
\mathrm{TiO}_{2} \rightleftharpoons \mathrm{Ti}_{\mathrm{i}}^{n+}+n e^{-}+\mathrm{O}_{2}(\mathrm{~g})
$$

for cation interstitials $\left(\mathrm{Ti}_{i}^{n+}\right)$ with $n$ positive charges (CI-type defects). As to $n$-values other than four, see under section 3.4 below.

In addition, there is also a hypothetical possibility of a stoichiometric defect equilibrium:

$$
\mathrm{Nil} \rightleftharpoons \mathrm{Ti}_{\mathrm{v}}^{\prime \prime \prime}{ }^{\prime}+\mathrm{Ti}_{\mathrm{i}}^{++++}
$$

involving titanium vacancies $\left(\mathrm{Ti}_{\mathrm{v}}{ }^{\prime \prime}{ }^{\prime \prime}\right)$.

The symbols' and - mean a negative and a positive surplus charge, respectively. $e^{-}$means a quasi-free electron, and "Nil" designates an ideal stoichiometric crystal.

In the following, we shall discuss the above possibilities on the basis of the ideal rutile structure itself and of other available data pertinent to the subject.

A critical discussion of results obtained up to 1954 has previously been given by Hauffe ${ }^{5}$, who concludes that the defect structure most likely is of the AVtype.

\subsection{Structural considerations}

Under section 2.0 is shown that the rutile structure contains favourable octahedral interstitial positions for titanium, and on this basis it seems likely that rutile should be an oxide of the metal excess type (CI-type) rather than of the oxygen deficient type (AV-type), and also that stoichiometric defects (Eqn. 3) could be present in rutile.

An interesting fact in this connection is that a $\mathrm{Ti}_{n} \mathrm{O}_{2 n-1}$-crystal structurally may be described ${ }^{7,9}$ as being composed of parallel sheet crystals of rutile, the "grain boundaries" between which are free of misfit and differ from the ideal rutile structure mainly in containing titanium in octahedral interstitial positions. At these "grain boundaries", the rutile layers are slightly displaced in relation to each other (see below). Were it not so, the $\mathrm{Ti}_{n} \mathrm{O}_{2 n-1}$-structures would have been identical to rutile with an ordered arrangement of titanium interstitials. It seems thus the most natural that in removing oxygen from rutile, one should go directly towards the $\mathrm{Ti}_{n} \mathrm{O}_{2 n-1}$-structures by forming titanium interstitials, and not make a roundabout way by first forming oxygen vacancies which then have to be eliminated (at least to a large extent) when the oxygen content of the highest member of the $\mathrm{Ti}_{n} \mathrm{O}_{2 n-1}$-series is reached (see under section 2.0). 

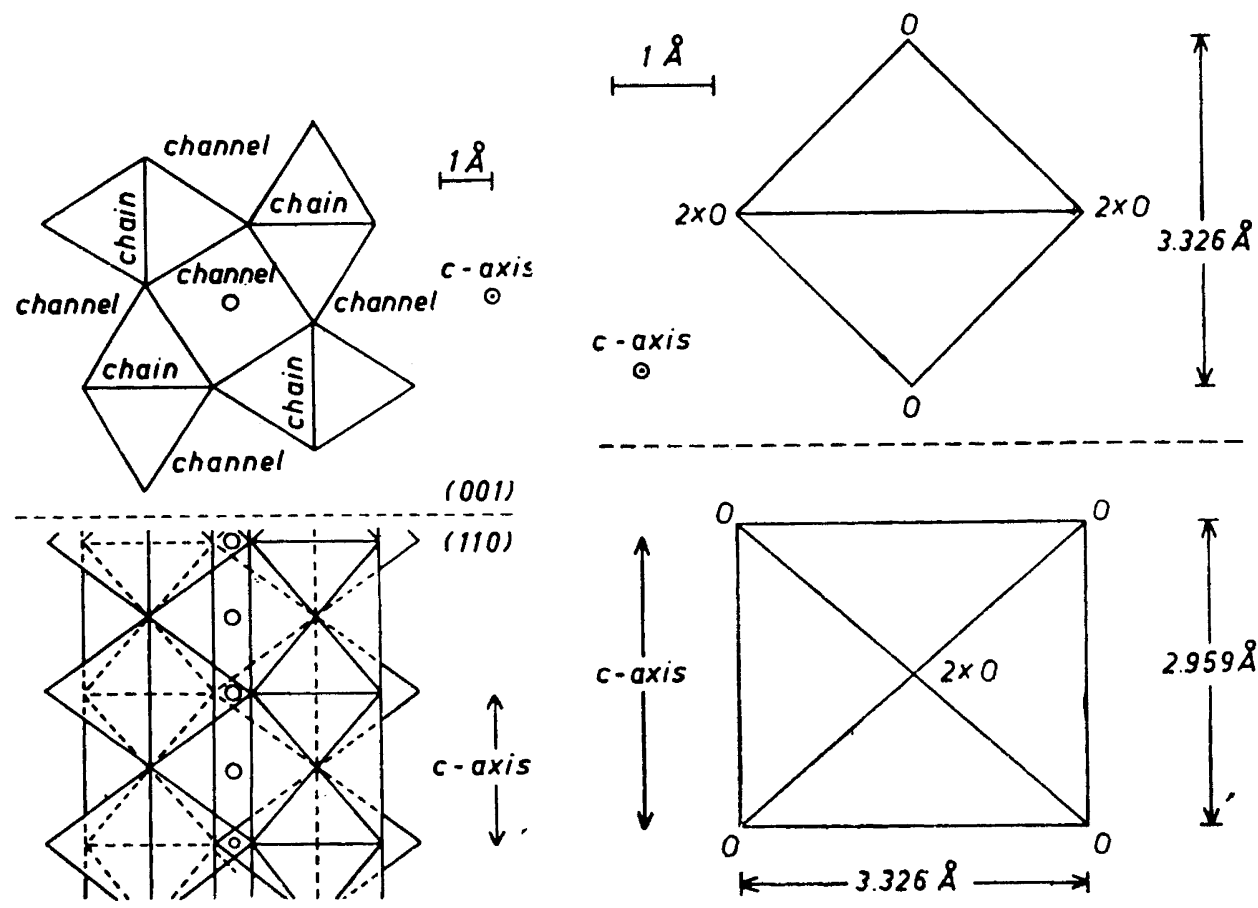

Fig. 3. Octahedral interstitial positions for Ti-ions in rutile.

Fig. 4. The shape and size of the $\mathrm{O}_{6}$-octahedra surrounding interstitial positions in rutile.

Magnéli and coworkers ${ }^{7}$ have further found that the rutile lattice is slightly expanded, especially normal to the $c$-axis, with decreasing oxygen content:

$$
\begin{array}{lll}
a=4.584 \AA, & c=2.959 \AA & \text { for maximum O-content } \\
a=4.603 \AA, & c=2.960 \AA & \text { for minimum O-content }
\end{array}
$$

It is difficult to judge what this expansion might really mean. If we assume, however, that rutile is a normal ionic crystal in which the lattice dimensions are mainly determined by the size of the ions, it is difficult to understand how the formation of oxygen vacancies may give such an effect. It is easier to imagine that the formation of titanium interstitials might cause a lattice expansion. The radius of the fourvalent titanium ion is namely about $20 \%$ too large to allow six surrounding oxygen ions to come into contact with each other. From Figs. 3 and 4 , it is further seen that a titanium interstitial should be expected to expand the lattice mainly in directions normal to the $c$-axis (just as observed).

It may seem that the above-mentioned displacement of the rutile layers at the "grain boundaries" or Magnéli-Andersson planes - as they better are

Acta Chem. Scand. 13 (1959) No. 2 
called - in the $\mathrm{Ti}_{n} \mathrm{O}_{2 n-1}$-structures, is merely so that the octahedron chains on one side of such a plane fit into the open octahedron channels on the other side of the plane and vice versa (see Fig. 3). The oxygen framework of the rutile structure is thus maintained essentially unaltered all through a $\mathrm{Ti}_{n} \mathrm{O}_{2 n-1^{-}}$ lattice. It is mainly the relative positions of the titanium ions in this framework that are changed at a Magnéli-Andersson plane. The titanium ions on one side of this plane are normally in positions which may be regarded as interstitial in relation to the rutile lattice on the other side of the plane and vice versa. Just at the plane, both the normal and the interstitial octahedron positions are occupied.

On this basis, the $\mathrm{Ti}_{n} \mathrm{O}_{2 n-1}$-structures could possibly be described as a rutile structure with ordered arrangements of titanium vacancies and titanium interstitials, the latter in excess. This may suggest that rutile itself also could have defects of this kind more or less randomly distributed in the lattice (see eqns. 2 and 3 ).

\subsection{Density measurements}

Ehrlich ${ }^{6}$ reports to have found a slightly lower density for $\mathrm{TiO}_{1.97}$ than for $\mathrm{TiO}_{2}$ by pycnometric measurements on powders. These results are used by Hauffe ${ }^{5}$ as one of the main arguments for the existence of AV-defects in rutile.

Ehrlich himself pointed out that his $\mathrm{TiO}_{1.97}$-sample was not quite a sound one. Pycnometric density measurements on powders are moreover easily affected with both systematic and accidental errors. As a comparison, we shall here give some density values determined by Magnéli and coworkers ${ }^{7}$ :

$d(\mathrm{TiO})=4.95, \quad d\left(\mathrm{TiO}_{1.67}\right)=4.20, \quad d\left(\mathrm{TiO}_{1.80}\right)=4.29 \mathrm{gcm}^{-3}$

and by Ehrlich ${ }^{6}$ :

$d(\mathrm{TiO})=4.89, \quad d\left(\mathrm{TiO}_{1.70}\right)=4.21 \quad d\left(\mathrm{TiO}_{1.80}\right)=4.17 \mathrm{gcm}^{-3}$

all of them on powders.

The inconsistence of these results should make it clear that, so far, one has to be careful in using the density data in elucidating the defect structure of rutile.

\subsection{Colour observations}

It is well known (see, e.g., Ref. ${ }^{5}$ ) that rutile acquires a dark grey-blue colour when kept in a reducing atmosphere at high temperatures, and that it is slightly coloured in this way also by the incorporation of a higher-valent metal oxide $\left(\mathrm{Ta}_{2} \mathrm{O}_{5}, \mathrm{Nb}_{2} \mathrm{O}_{5}, \mathrm{Sb}_{2} \mathrm{O}_{5}\right.$ or $\left.\mathrm{WO}_{3}\right)$.

Hauffe ${ }^{5}$ has suggested that this may be due to a formation of Pohl-Schottky colour centres, the so-called F-centres. Such a centre is equivalent to an oxygen vacancy with a trapped electron $\left(\mathrm{O}_{\mathrm{v}} \cdot e^{-}\right)$. The colouring of rutile, therefore, has naturally been used as another argument in favour of a defect structure of the AV-type. 
A threevalent titanium ion in rutile may also give rise to a blue colour, however, and - in our opinion - the significance of the colour change is not understood well enough for the present to be used as an argument in this discussion.

\subsection{Conductivity measurements}

According to the Schottky-Frenkel theory of reversible defects ${ }^{10,11}$, a defect equilibrium is given by the mass action law in quite an ordinary way. The equilibria of the defect systems (1), (2), and (3) above, should thus be represented by the following equations:

and

$$
\begin{aligned}
& \left(\mathrm{O}_{\mathrm{v}}^{*}\right)\left(e^{-}\right)^{2} p^{1 / 2}=\text { const. } \\
& \left(\mathrm{O}_{\vec{v}} \cdot e^{-}\right)\left(e^{-}\right) p^{1 / 2}=\text { const. } \\
& \left(\mathrm{O}_{\mathrm{v}}^{*} 2 e^{-}\right) p^{3 / 2}=\text { const. }
\end{aligned}
$$

and

$$
\left(\mathrm{Ti}_{\mathrm{i}}^{n+}\right)\left(e^{-}\right)^{n} p=\text { const. }
$$

$$
\left(\mathrm{Ti}_{\mathrm{i}}^{++++}\right)\left(\mathrm{Ti}_{\mathrm{v}}^{\prime \prime \prime}{ }^{\prime \prime}\right)=\text { const. }
$$

where $p$ means the partial pressure of $\mathrm{O}_{2}$ in the gas phase, and the brackets indicate that it is the concentration of the defect species we are dealing with in these equations. The constants are of course temperature dependent.

If we now assume that the conductivity $(q)$ of rutile is proportional to the concentration of quasi-free electrons, we easily have by combining the eqns. (1) and (4) that

$$
\begin{aligned}
& q=\text { const. } p^{-1 / 6} \\
& q=\text { const. } p^{-1 / 4} \\
& q=\text { const. (independent of } p \text { ) }
\end{aligned}
$$

in the case of oxygen vacancies with none, one, or two trapped electrons, respectively.

In the case of a defect structure of the CI-type, we have

$$
q=\text { const. } p^{-1 / n+1}
$$

This is easily seen by combining the eqns. (2) and (5).

Hauffe and coworkers ${ }^{5,12}$ have found that the conductivity of rutile is proportional to $p^{-1 / 4.5}$ to $p^{-1 / 5}$ in the temperature range $800-1000^{\circ} \mathrm{C}$. This may be explained on the assumption of three- and fourvalent titanium ions in interstitial positions ( $n=3$ and 4 in eqn. 8 ). The results are not compatible with a defect structure of the AV-type.

It could here possibly be argued that a threevalent titanium ion is equivalent to a quasi-free electron and that it has no sense to use other $n$-values than four in eqns. (2), (5), and (8). This cannot be quite correct, however.

Acta Chem. Scand. 13 (1959) No. 2 
Cronemeyer ${ }^{13}$ has namely shown that the electronic conductivity of rutile is distinctly higher in direction of the c-axis than in a direction normal to this axis, and as there is practically no possibility for interstitial titanium ions to take part in an electron exchange in the $c$-direction, whereas this may seem a preferred exchange direction for titanium ions in normal lattice positions when judging from interatomic distances (see Fig. 3), a threevalent titanium interstitial ion cannot be regarded synonymous with a quasi-free electron. There is at least a distinct difference between interstitially and normally placed titanium ions in this respect. This may easily be seen from the description of the rutile structure under section 2.0 above.

A combined stoichiometric and non-stoichiometric defect equilibrium in rutile should be defined by the following simultaneous equations:

$$
\begin{aligned}
& \left(\mathrm{Ti}_{\mathrm{i}}^{++++}\right)\left(\mathrm{Ti}_{\mathrm{v}}{ }^{\prime \prime \prime}\right)=k_{1} \\
& \left.\mathrm{Ti}_{\mathrm{i}}^{++++}\right)\left(e^{-}\right)^{4} p=k_{2} \\
& 4\left(\mathrm{Ti}_{\mathrm{i}}^{++++}\right)=4\left(\mathrm{Ti}_{\mathrm{v}}^{\prime \prime \prime}\right)+\left(e^{-}\right)
\end{aligned}
$$

The two first equations are the same as (5) and (6) above. The last equation is required by the electroneutrality principle, and the two last equations imply the simplifying assumption that $n=4$ in eqn. (2).

By solving this equation system, we easily have:

$$
\left(e^{-}\right)^{5}\left(4 k_{1}\left(e^{-}\right)^{3} p+k_{2}\right)=4 k_{2}^{2} p^{-1}
$$

which should represent the conductivity/oxygen pressure relationship in this case, when the conductivity is assumed proportional to the concentration of quasi-free electrons.

In case $4 k_{1}\left(e^{-}\right)^{3} p<<k_{2}$, this equation reduces to:

$$
\left(e^{-}\right)=\left(4 k_{2}\right)^{1 / 5} p^{-1 / 5}
$$

which is equivalent with the previous eqn. (8), showing the conductivity to vary inversely with the $1 / 5$-power of the oxygen partial pressure when $n=4$.

In case $\left.4 k_{1}\left(e^{-}\right)^{3} p\right\rangle k_{2}$, eqn. (10) reduces to:

$$
(\bar{e})=\left(k_{2}^{2} / k_{1}\right)^{1 / 8} p^{-1 / 4}
$$

whereby it is seen that the presence of a stoichiometric defect equilibrium in addition to a non-stoichiometric one should make the conductivity $q$ to be relatively more sensitive $(d \log q)$ to relative changes $(d \log p)$ in the oxygen pressure $p$.

The conductivity/pressure relationships found by Hauffe and coworkers ${ }^{12}$ could possibly be interpreted also along this line of thought.

The conductivity measurements referred to, have been made on powders. The above discussion does show, however, that even single crystal data of this kind may not be quite conclusive in determining the defect structure of rutile. 


\subsection{Weight change measurements}

From eqns. (1) and (2) is seen that a rutile crystal should loose some oxygen and, thereby, decrease in weight on the formation of defects. By also taking eqns. (4) and (5) into consideration, we easily bave for the equilibrium weight:

$$
\begin{gathered}
w=w_{0} \text { - const. } p^{-1 / 6} \\
w=w_{0} \text { - const. } p^{-1 / 4} \\
w=w_{0} \text { - const. } p^{-1 / 2}
\end{gathered}
$$

in the case of $\mathrm{AV}$-defects with none, one, and two trapped electrons, respectively, and

$$
w=w_{0} \text { - const. } p^{-1 / n+1}
$$

in the case of CI-defects with $n$ positive charges.

$w_{0}$ means here the weight of the crystal when without defects. Buessem, Förland, T., Förland, K.S., and Marshall ${ }^{14}$ have studied the equilibrium weight of a rutile sample (powder) as a function of the oxygen pressure (from about 10 to 760 torr) at temperatures from 860 to $1050^{\circ} \mathrm{C}$. Their results are apparently best in agreement with (13a) above, thereby indicating a defect structure of the AV-type.

As their rutile sample was not quite pure, and, considering the very small difference between a 1/6- and a 1/5-power relationship, we don't feel quite convinced that the former and not the latter is the correct one. The latter relationship is more consistent with the results of the conductivity measurements (see above), and is the one to be expected if the defect structure is of the CI-type ( $n=4$ in eqn. (14) above).

Förland ${ }^{15}$ is now making renewed and extended weight change measurements on a high purity rutile sample, and it shall be interesting to see the results of these measurements.

\subsection{In corporation experiments}

It is well known that an incorporation of even small amounts of foreign ions into a host lattice may drastically change its defect equilibrium, and that a knowledge of the effect of such incorporations on various properties of a crystal may assist in elucidating its original defect structure (see, e.g., Ref. ${ }^{5}$ ).

In the case of rutile, we are only aware of data on the effect of incorporations on its electronic conductivity and on its oxidation protective properties when present as a film on titanium. The latter effect will be discussed under a later section (3.7), and we shall here only deal with the former effect.

If rutile should have a defect structure purely of the AV-type, it seems natural to assume that the cation interstitial positions in this lattice - for one reason or another - must be so unfavourable that not even incorporated cations will make use of them. An incorporation of a foreign metal oxide must then take place in a way as here exemplified by $\mathrm{Cr}_{2} \mathrm{O}_{3}$ :

$$
\mathrm{Cr}_{2} \mathrm{O}_{3}+2 e^{-}+\frac{1}{2} \mathrm{O}_{2}=2 \mathrm{Cr}_{\mathrm{S}}^{\prime}(\mathrm{Ti})+2 \mathrm{TiO}_{2}
$$

Acta Chem. Scand. 13 (1959) No. 2 
$\mathrm{Cr}_{\mathbf{s}}^{\prime}(\mathrm{Ti})$ means here a threevalent chromium ion substituting a fourvalent titanium ion, and this represents one negative surplus charge in the lattice.

From this equation is seen that the incorporation of a cation of lower valence than four should lead to a consumption of free electrons and, thereby, to a decrease in electronic conductivity in the case of AV-defects in rutile. Small amounts of $\mathrm{Ga}_{2} \mathrm{O}_{3}, \mathrm{Al}_{2} \mathrm{O}_{3}$, and $\mathrm{NiO}$ have been found ${ }^{5}$, however, to have almost no effect on the conductivity, and $\mathrm{Cr}_{2} \mathrm{O}_{3}$ even to increase the conductivity at temperatures below $900^{\circ} \mathrm{C}$.

These observations are perhaps easier explained on the assumption of a defect structure of the CI-type in rutile. In this case we should be allowed to assume that also foreign cations could enter into interstitial positions in the rutile lattice. Thus, by once more taking $\mathrm{Cr}_{2} \mathrm{O}_{3}$ additions as an example, and by assuming this oxide to be built into the rutile lattice in such a simple way as to give a fraction $x$ of the $\mathrm{Cr}^{+++}$-ions as substitutes for $\mathrm{Ti}^{++++}$-ions in normal lattice positions:

$$
x \mathrm{Cr}_{2} \mathrm{O}_{3}+2 x e^{-}+\frac{x}{2} \mathrm{O}_{2}=2 x \mathrm{Cr}_{\mathrm{s}}^{\prime}(\mathrm{Ti})+2 x \mathrm{TiO}_{2}
$$

and the remaining fraction $(1-x)$ of the $\mathrm{Cr}^{+++}$-ions, in interstitial positions:

$$
(1-x) \mathrm{Cr}_{2} \mathrm{O}_{3}=2(1-x) \mathrm{Cr}_{\mathrm{i}}^{+++}+6(1-x) e^{-}+\frac{3(1-x)}{2} \mathrm{O}_{2}
$$

the total incorporation is represented by:

$\mathrm{Cr}_{2} \mathrm{O}_{3}=2 x \mathrm{Cr}_{\mathrm{s}}^{\prime}(\mathrm{Ti})+2(1-x) \mathrm{Cr}_{\mathrm{i}}^{+++}+2(3-4 x) e^{-}+2 x \mathrm{TiO}_{2}+\frac{3-4 x}{2} \mathrm{O}_{2}$

From this equation is seen that the effect of $\mathrm{Cr}_{2} \mathrm{O}_{3}$-additions on the conductivity of rutile in this case should depend on the fraction factor $x$ (for $x \gtreqless \frac{3}{4}$ we will have for the conductivity $\Delta q \lesseqgtr 0$ ). This factor may very well be a function of both $\mathrm{Cr}_{2} \mathrm{O}_{3}$-concentration, temperature, and oxygen pressure, and eqn. (16) could thus possibly explain the observed effects of these variables on the conductivity of the $\mathrm{TiO}_{2} / \mathrm{Cr}_{2} \mathrm{O}_{3}$ mixed oxides (see Ref. ${ }^{5}$ ).

A similar treatment could be given also to other rutile/foreign oxide systems.

\subsection{Oxidation studies}

Through studies of the oxidation of titanium under conditions at which rutile is formed on the metal surface, it should also be possible to gain some information as to the defect structure of rutile.

Most of the previous work on the oxidation of titanium is reviewed by Kofstad and Hauffe ${ }^{3}$ and by Kofstad, Hauffe, and Kjöllesdal ${ }^{4}$. Some further work is now being prepared for publication by Hurlen, Kjöllesdal, Markali and Norman.

In this latter work, rather strong evidence is found that the oxidation, at temperatures from 300 to $500^{\circ} \mathrm{C}$, is governed by a cavity formation at the metal oxide interface. Such a cavity formation is probably most easily understood by assuming the occurrence and growth of cavities to be due to a reten- 
tion at the metal/oxide interface of inward diffusing metal ion vacancies or of vacancies left behind in the metal when metal ions enter into interstitial positions in the oxide and migrate outwards.

In the same work is also found that rutile whiskers sometimes are formed on top of the rutile film, and Kinna and Knorr ${ }^{16}$ have found that platinum markers placed on a titanium surface, are deeply buried by the rutile layer formed during oxidation at 1000 and $1200^{\circ} \mathrm{C}$. All these observations are difficult to understand without assuming a preferential titanium diffusion in rutile.

Also Gulbransen and Andrew ${ }^{17}$ assume mainly a titanium diffusion in the oxide film all over the temperature region $\left(250-600^{\circ} \mathrm{C}\right)$ covered by their oxidation experiments, and, in the relatively high negative activation entropy of oxidation calculated from the results of these authors, Moore ${ }^{18}$ finds theoretical evidence for the validity of this assumption.

Most of the workers within this field seem to assume a preferential oxygen diffusion in rutile, however, and, from marker studies with radioactive silver at $900^{\circ} \mathrm{C}$, Davies and Birchenall ${ }^{19}$ got some results which have been taken as being in favour of this assumption even though they are not quite conclusive.

As the diffusion in solids may be regarded a diffusion of defects, it seems that the results of the oxidation studies are more in accordance with a defect structure of the CI-type (or a combined CI/CV-type) than with one of the AV-type.

The fact that the Wagner-Hauffe ${ }^{2}$ approach to alloy oxidation has proved unsuccessful in the case of titanium ${ }^{20}$ may also have some explanation ${ }^{21}$ on the assumption of a combined CI/CV defect structure in rutile. The WagnerHauffe theory does not take such a combined defect structure into account. It only applies to cases in which the oxide has a single defect system.

\subsection{CONCLUSION}

The defect structure of rutile has here been discussed on the basis of structural considerations, density measurements, colour observations, conductivity measurements, weight change measurements, incorporation experiments, and oxidation studies.

It has been shown that some of the available data are inconclusive, that some data (especially those by Marshall and Förland ${ }^{\mathbf{1 4}}$ on the equilibrium weight of a rutile sample as a function of the oxygen pressure) may indicate a defect structure of the anion vacancy type (AV-type), but that the majority of the data is most easily interpreted on the assumption of a defect structure of the CI-type (or a combined CI/CV-type).

The strongest evidence in favour of this assumption is that the rutile structure contains apparently very favourable octahedral interstitial positions for titanium ions, and that positions of this kind actually are being occupied in an ordered way in the rutile-like oxides belonging to the homologous series of formula $\mathrm{Ti}_{n} \mathrm{O}_{2 n-1}$ (see Ref. ${ }^{7}$ ). This series of oxides extends directly up to the lower $\mathrm{O}$-limit of the homogeneity range of the $\mathrm{TiO}_{2}$ (rutile), and it seems logical and natural that we here should have just a transition from an ordered to a random occupancy of such sites.

Acta Chem. Scand. 13 (1959) No. 2 
Acknowledgement. This work forms part of a research project sponsored by the Air Research and Development Command, US Air Force, through its European Office under Contract AF 61(514)-892.

The author is much indebted to Dr. A. Magnéli and Dr. S. Andersson at the University of Stockholm, to Siv. ing. K. Seip Förland and Dr. T. Förland at the Technical University of Norway, Trondheim, and to Dr. N. Norman, Cand. real. J. Markali, Siv. ing. H. Kjöllesdal and other members of the staff at the Central Institute for Industrial Research, Blindern, Oslo, Norway, for helpful discussions.

\section{REFERENCES}

1. Wagner, C. Z. physik. Chem. (B) 21 (1933) 25.

2. Hauffe, K. Oxydation von Metallen und Metallegierungen, Springer Verlag, Berlin 1956.

3. Kofstad, P. and Hauffe, K. Werkstoffe u. Korrosion 7 (1956) 642.

4. Kofstad, P., Hauffe, K. and Kjöllesdal, H. Acta Chem. Scand. 12 (1958) 239.

5. Hauffe, K. Reaktionen in und an Festen Stoffen, Springer Verlag, Berlin 1955.

6. Ehrlich, P. Z. Elektrochem. 45 (1939) 362; Z. anorg. allgem. Chem. 247 (1941) 53.

7. Andersson, S., Collén, B., Kuylenstierna, U. and Magnéli, A. Acta Chem. Scand. 11 (1957) 1641

8. Cromer, D. T. and Herrington, K. J. Am. Chem. Soc. 77 (1955) 4708.

9. Andersson, S. Private communication.

10. Shottky, W. Z. physik. Chem. (B) 11 (1930) 163.

11. Frenkel, J. Z. Physik. 35 (1926) 652.

12. Hauffe, K., Grunewald, H. and Tränkler-Greese, R. Z. Elektrochem. 56 (1952) 937.

13. Cronemeyer, D. C. Electrical and Optical Properties of Rutile Single Crystals, Technical Report 46, Laboratory for Insulation Research, M.I.T., August 1951.

14. Buessem, W., Förland, T., Förland, K. S. and Marshall, P. A. Linden Laboratories, State College, Pa., U.S.A. Private communication with Mrs. K. Seip Förland.

15. Förland, K. S. Private communication.

16. Kinna, W. and Knorr, W. Z. Metallkunde 47 (1956) 594.

17. Gulbransen, E. A. and Andrew, K. F. Met. Trans. 185 (1949) 741.

18. Moore, W. J. J. Elektrochem. Soc. 100 (1953) 302 (appendix).

19. Davies, M. H. and Birchenall, C. E. J. Metals 3 (1951) 877.

20. Kofstad, P. Investigation of the Mechanism of Oxidation of Titanium and Titanium Alloys at High Temperatures, $A R D C$-Report, Central Institute for Industrial Research, Blindern, Oslo, Norway, April 1957.

21. Hurlen, T., Kjöllesdal, H., Markali, J. and Norman, N. Oxidation of Titanium, $A R D C$-Report, Central Institute for Industrial Research, Blindern, Oslo, Norway, April 1958.

Received November 18, 1958. 